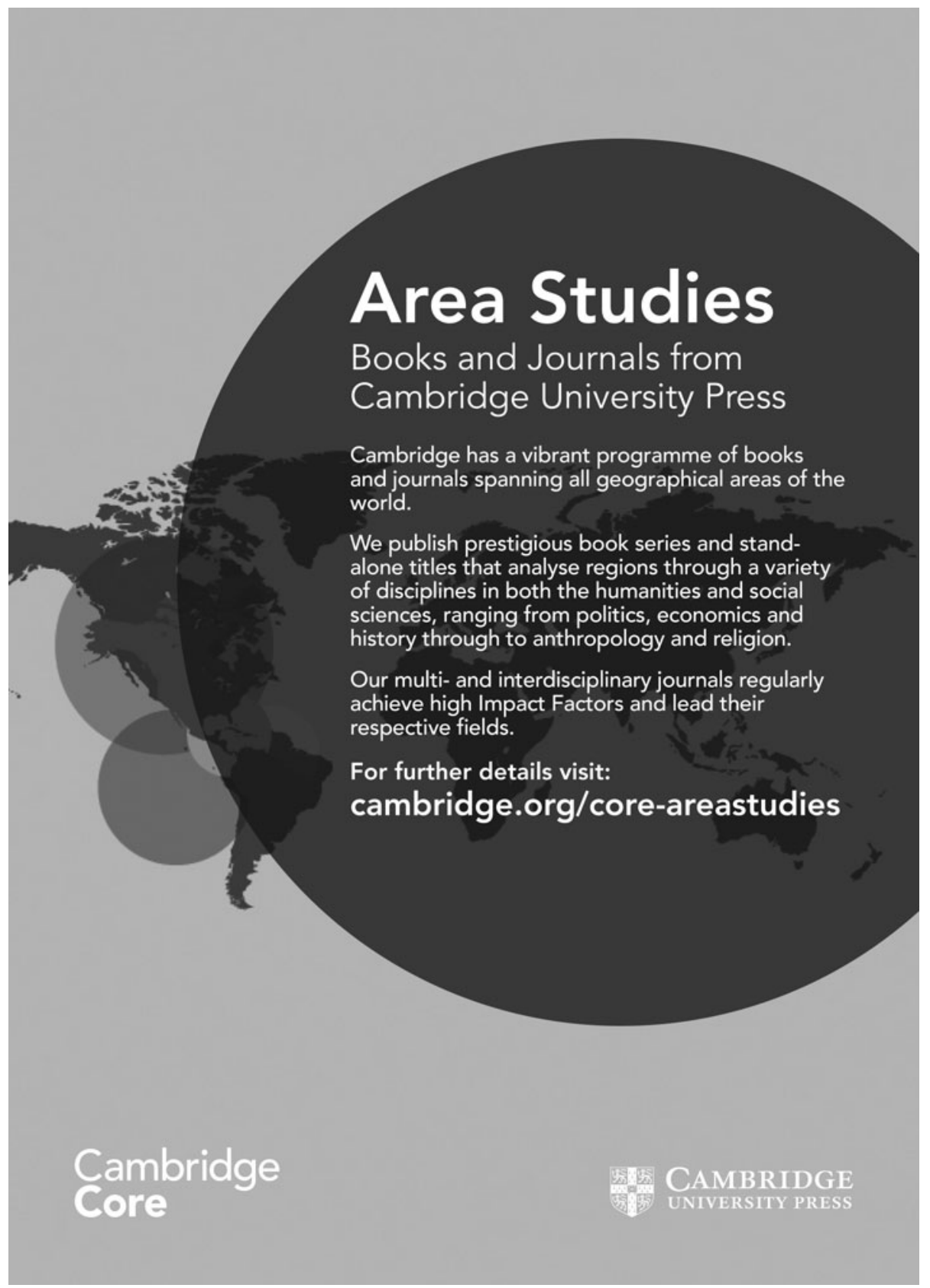


The Tang Center for Early China at Columbia University was founded in 2015 through a generous endowment gift from Oscar Tang and Agnes Hsu-Tang. The Tang Center is dedicated to the advancement of the understanding of the richness and importance of early Chinese civilization as a part of a broader common human heritage. It is committed to doing so through both solid scholarship and broad public outreach. The Tang Center sponsors a variety of conferences, workshops as well as public lectures each year including the Columbia Early China Seminar. The Tang Center is especially interested in supporting research initiatives that aim to examine newly discovered paleographic and textual material as well as artifacts, and in promoting the role of archaeology as a path to understand the past.

\section{Call for Manuscripts}

\section{Tang Center Series in Early China}

Sponsored by the Tang Center and to be published by Columbia University Press, the "Tang Center Series in Early China" includes new studies that make major contributions to our understanding of early Chinese civilization or that which break new theoretical or methodological grounds in Early China studies. The series is especially interested in publishing works that analyze newly discovered paleographic and manuscript materials as well as archaeological data. Disciplinary focuses of the series are history, archaeology, art history, anthropology, literature, philosophy, and the history of sciences and technology. The series spans from the Neolithic period to the end of the Han Dynasty (AD 220), or to the end of the Tang Dynasty (AD 907) for titles in archaeology. All submissions are subject to peer reviews and editorial evaluation. For more information, please see http://tangcenter-columbia. org/publications/. Interested authors should submit a book proposal (maximum 25 manuscript pages), accompanied by CV, to: info@tangcenter-columbia.org, or by mail to: 509 Kent Hall, 1140 Amsterdam Avenue, MC 3907, Columbia University, New York, NY 10027.

\section{Call for Applications}

\section{The Tang Post-Doctoral Research Award in Early China Studies}

The Tang Center for Early China offers one Post-Doctoral Research Award in the amount of $\$ 15,000$ each year in recognition of outstanding research projects in early Chinese civilization or in archaeology.

\section{The Tang Visiting Scholar's Fellowship}

The Tang Center offers Visiting Scholar's Fellowship each year to one scholar for an in-residence research period of 10 months at Columbia University, or to two scholars for a period of 5 months each, depending on the need of the proposed projects. The applicant must be non-US based.

\section{Workshop and Conference Grants}

The Tang Center offers grants in the amount of $\$ 13,000$ each to up to two workshop and/or conference proposals each academic year, depending on the scale. Each workshop or conference should have an identified central problem or theme on which the papers will focus. Alternatively, the workshop/ conference can be centered on a newly discovered corpus of materials or manuscripts, or on an important archaeological site, or a region.

Application deadline, November 30 , for all programs.

For more information, please visit our website www.tangcenter-columbia.org. Questions directed to: info@tangcenter-columbia.org; or by phone: 212.854.5546. 


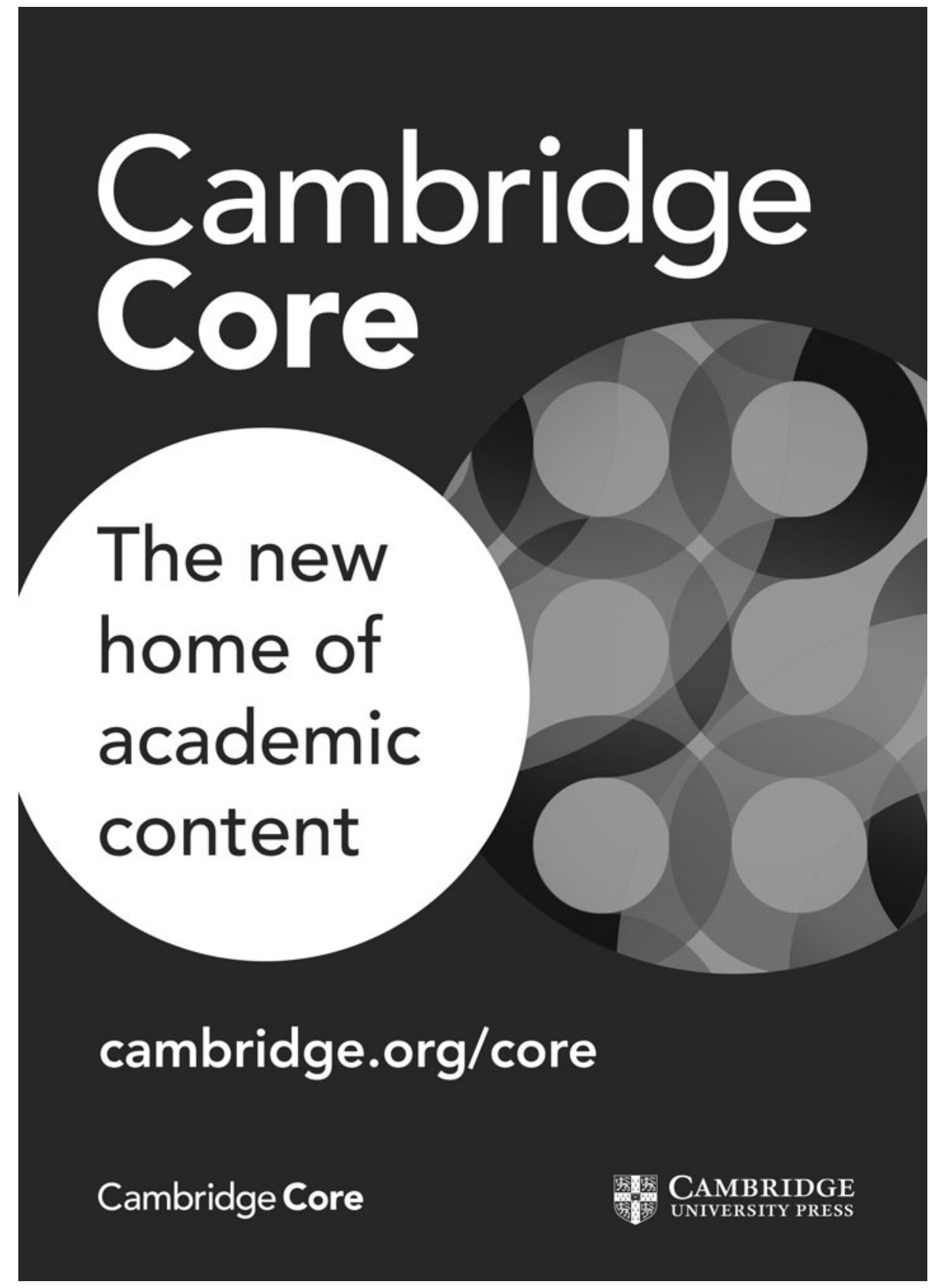




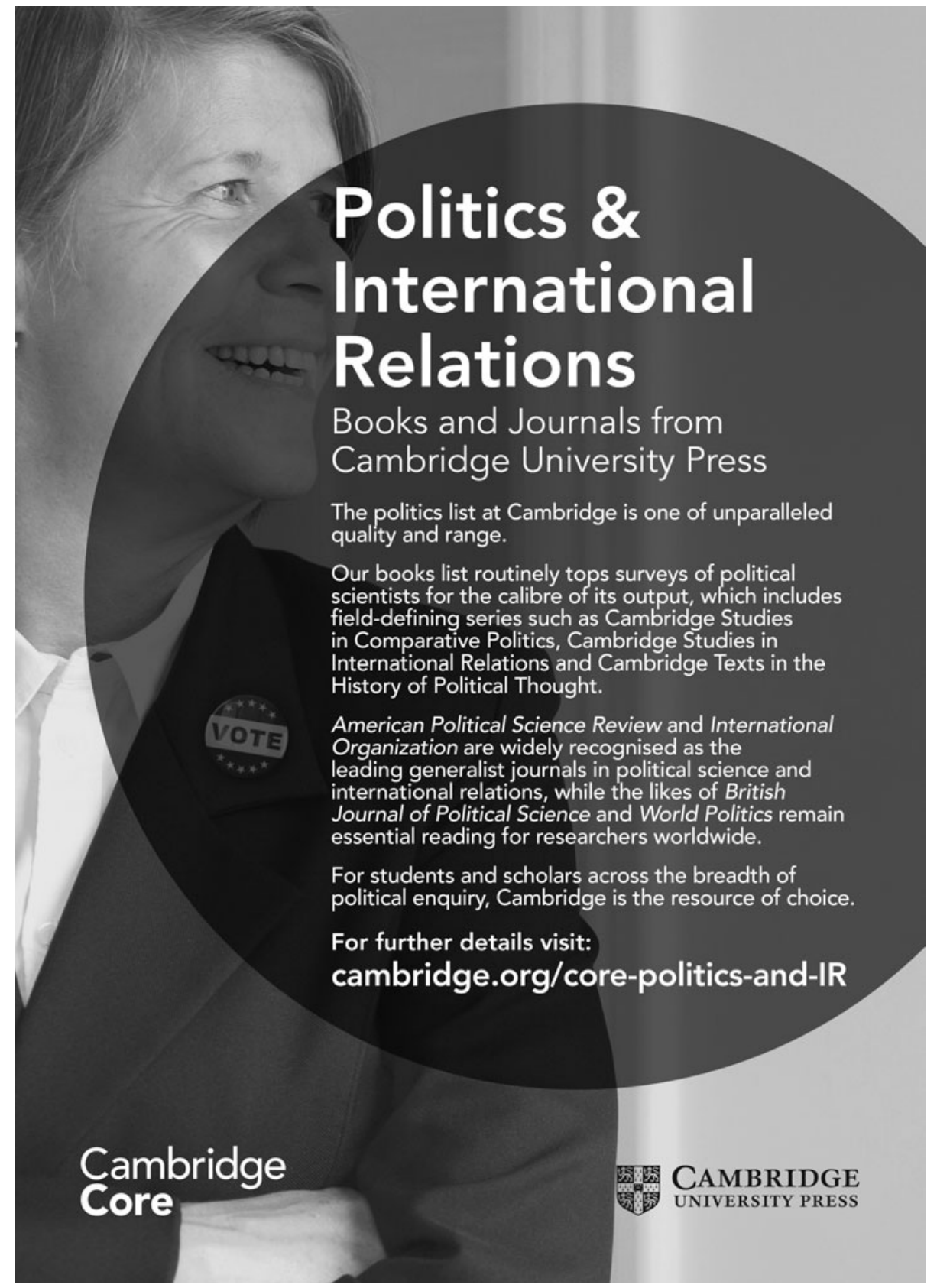




\section{JOURNAL OF EAST ASIAN STUDIES}

\section{Contents}

VOLUME 17 · ISSUE 2 - JULY 2017

\section{Articles}

145 Media Exposure and Regime Support Under Competitive

Authoritarianism: Evidence from South Korea

Joan E. Cho, Jae Seung Lee, and B.K. Song

167 Cadre Rotation and Campaign Mobilization in China's Anticorruption Enforcement

Qingjie Zeng

191 Who Wants to Leave China?

\section{Haifeng Huang}

215 Electoral Formula and Fragmentation in Hong Kong

John M. Carey

\section{Research Note}

233 Taiwan Citizens' Views of China: What Are the Effects of Cross-Strait Contacts?

\section{T.Y. Wang and Su-feng Chang}

245 Book Reviews

255 Addenda 